\title{
Postdigital Positionality as a Teacher
}

\author{
Measuring What Exactly, and Why?
}

At the beginning of The Labour of Words in Higher Education, I asked the question, when did the academic labour of teaching become 'best practice? The use of this phrase seemed to appear in policy discourse about education during the 199os as something teachers should aspire to providing, alongside mantras where academics needed to respond to the demands of a 'knowledge-based economy' (KBE), to be ready for an 'information age' and to ensure 'competitive advantage' in the 'global marketplace' (Hayes, 2019a). The opaque notion of best practice is not confined to education and has been picked up across many professions and workplaces, but others too, have called for a different discourse, one more 'relevant' to individuals, communities and universities (Hambleton, 202O). Not unlike some biological viruses, policy discourse of this kind seems to take on a form of contagion in our language, as described by Mann (2018) and linger in the atmosphere of HE. Through complex integrations of human and digital systems, such discourse seems to be 'self-renewing' (Peters, 2012). When I critiqued the linguistic structuring of HE McPolicy I argued that multiple repetitions of statements like these are problematic when phrases (not people) enact academic activities:

World class research and engaging teaching approaches provide an excellent learning experience.

Support and celebrate innovations and best practice in enhancing the student experience. (Hayes, 2019a: 85)

Not only do these statements omit any direct reference to the academic labour involved in teaching students and in student learning, they are also hard to contest. The concepts expressed sound as if they are positive ones, yet they arouse disquiet when considered next to what we each personally experience in diverse contexts as teachers. Like many educational buzz phrases, the notion of 'measuring excellence' is an approach that has taken on a viral nature in recent years in HE policy discourse. Biesta (2009) argues that:

the rise of the measurement culture in education has had a profound impact on educational practice, from the highest levels of educational 
policy at national and supra-national level down to the practices of local schools and teachers. (Biesta, 2009)

There are though, irrationalities that emerge from rational forms of 'measuring excellence' when an expression of implied values in McPolicy tends to close down any further need to 'engage explicitly with values in our decisions about the direction of education' (Biesta, 2009). Teacher positionalities are altered in this situation too because the impression that we are all proceeding 'towards a pre-specified end' requires no further debate. Biesta provides an example in the emphasis placed on the idea of 'educational effectiveness':

Effectiveness is an instrumental value, a value which says something about the quality of processes and, more specifically, about their ability to bring about certain outcomes in a secure way. But whether the outcomes themselves are desirable is an entirely different matter - a matter for which we need value-based judgements that are not informed by instrumental values but by what we might best call ultimate values: values about the aims and purposes of education. (Biesta, 2009)

Due to recent technological and cultural shifts, education may now have an ultimate value in supporting human endeavours for survival in the context of biodigital convergence and our societal response (UNESCO, 2020d). How an emphasis on sustainability (UNESCO, 2020: 65) might help to disrupt a 'meansend' consumer based approach that has persisted over decades (Hlynka \& Belland, 1991:v) remains part of this debate. Through a postdigital perspective we might ask too which former educational models might be revisited, discarded or redesigned, as 'advances in the biological sciences, including psychophysiology and biometrics, neuroscience and genomics' bring 'fresh questions about the intersections of biology with society, politics and governance' (Williamson, 2019).

Then there are the value-based judgements that relate to the positionality of each individual teacher, which are complex and fluid, enmeshed in power relations and contextually bound (Torres, Olave \& Lee, 2019). As such, teachers are ideally placed to raise critical questions concerning the purpose and direction of educational processes and practices amid postdigital change. However, in Pauline Palmer's exploration of the positionality and agency of teacher educators working in $\mathrm{HE}$, she found that powerful neoliberal discourses required teachers to 're-position themselves'. This has had varying degrees of success and has come at a high price in terms of a 'deep sense of loss of professional agency and identity' (Palmer, 2017). 
In Pursuing Teaching Excellence in Higher Education: Towards an Inclusive Perspective, Wood and $\mathrm{Su}(2 \mathrm{O2O})$ argue that despite the international significance placed on the idea of 'teaching excellence' for $\mathrm{HE}$ worldwide, the notion is opaque and poorly defined. The importance of engaging multiple voices in discussions of what teaching excellence might entail is emphasised. There is a need to adopt different lenses and a take a plurality of stakeholder perspectives into account. Given that $\mathrm{HE}$ is a vital element of the public sphere, they claim that vitality is diminished when an ideologically informed discourse prevails in the absence of informed public debate and more democratic and inclusive perspectives (Wood \& $\mathrm{Su}, 2 \mathrm{O2O}$ ). Whilst these arguments support positionality from a human vitality perspective, there are others who would broaden these arguments further, to include more relational elements that are not all human.

For Gravett and Kinchin (2020), it is necessary to rethink the contested concept of 'teaching excellence' in HE via posthumanist theory, because this helps to shift the gaze beyond the measured individual to explore a wider context of relationality and fluidity of practice. There is a need to avoid what has become a 'sedative discourse' (Guattari, 2014: 27) that closes down debate rather than inviting criticality. Thus, extending debate to include ecological crises resulting from the expansion of capitalism brings in arguments that link education with recent global challenges and all living and technological systems. This perspective is consistent with a growing emphasis across the globe on sustainability as a much broader shared goal internationally, that is closely linked to education. At the same time as legislation and agreements amongst international partners to improve global environmental standards and to develop a circular bioeconomy based on biodigital progress (Peters, Jandrić \& Hayes, 2021b), the role of education is being recast in more ecological models (Bronfenbrenner, 1994, Fawns, Aitken \& Jones, 2020) and exploratory postdigital ecopedagogies (Jandrić \& Ford, 2020).

Saachi, Lotti \& Branduardi place education at the centre of a model for a bio-based economy, arguing that more flexible educational frameworks are needed to facilitate the new interdisciplinary combinations we will require to meet sustainability goals. They suggest that education will need to cross the boundaries of a single sector and begin to integrate tools, language and knowledge drawn from across different disciplines and sub-disciplines. The design of 'high-level education programmes' that cut across subjects such as science, innovation, economics and education are more likely 'to promote and guide society towards bio-based innovation' (Saachi, Lotti \& Branduardi, 2020). In the United Nations Educational, Scientific and Cultural Organization (UNESCO) report on Education for Sustainable Development (ESD) (2O2Od) a 
roadmap is provided to support such change where the primary emphasis is placed on learning to live sustainably on the planet. The UNESCO 2030 agenda also recognises that alongside addressing the 17 Sustainable Development Goals (SDGs) intended to eradicate poverty, education can no longer afford not to engage with the implications of a new biodigital context, where: 'the tipping points will eventually change not only our lives and environments, but also our discourse on sustainability. Some 'old' problems will be resolved, but new challenges and risks will arise. ESD for the future cannot afford not to address the implications of the technological era (UNESCO, 2O2Od).

In this chapter, the positionality of teachers is examined firstly, in relation to the culture of measuring excellence and performativity that has been adopted and absorbed across HE in recent decades. Biesta (2009) argues that this has marginalised the question of 'purpose' in educational discussions. The question of what gets included and audited, and what becomes excluded in this discourse, is significant in relation to inclusivity policies and frameworks. This is because a narrow framing of McDonaldisation of HE (Hayes, D., 2017) has yielded a 'macho consumerist identity' (Bartram, 2020) that teaching, and teachers, are constrained by. This has redefined teacher identities within one narrow, rational purpose but has irrationally closed down other more inclusive areas of exploration that acknowledge the positionality of teachers and students in postdigital society. Whilst new lecturers spend considerable time learning and discussing powerful educational theories and models, as well as exploring their own identities as educators, much of this positionality gets erased in a model of competition and compliance. A separation of learners from the broader context and relationships that exist and develop through education are discussed. We seem to have been laying a rather narrow path for A to be applied in education to follow a diminished 'learner centred' model of teaching in which the key dimensions of McDonaldisation appear to be alive and well. This marketised, metrics-based approach makes assumptions about what should be measured, but it also excludes many key aspects of our postdigital lives, in its own form of 'cancel culture'.

In the second half of the chapter new personal and plural starting points are explored. The pandemic has taken the majority of teaching abruptly into online contexts and also into the homes of students and teachers. With little time to prepare or reflect on this 'pivot', the question of positionality has come to the forefront as students and teachers have shared their individual narratives. Individuals relate many knock-on or compounded effects that are relevant to equality, diversity and inclusivity policy. Some have gained new skills, others merely new anxieties. The challenge of sharing inadequate workspaces and equipment has been voiced, setbacks to gender equalities as childcare, 
home schooling and caring responsibilities have added pressures to already busy academic lives, less travel has been welcomed by some (Figure 39), but for others less accessibility to support for disability has been raised (Jandrić \& Hayes, 2020a, Jandrić \& Hayes, 2020b).

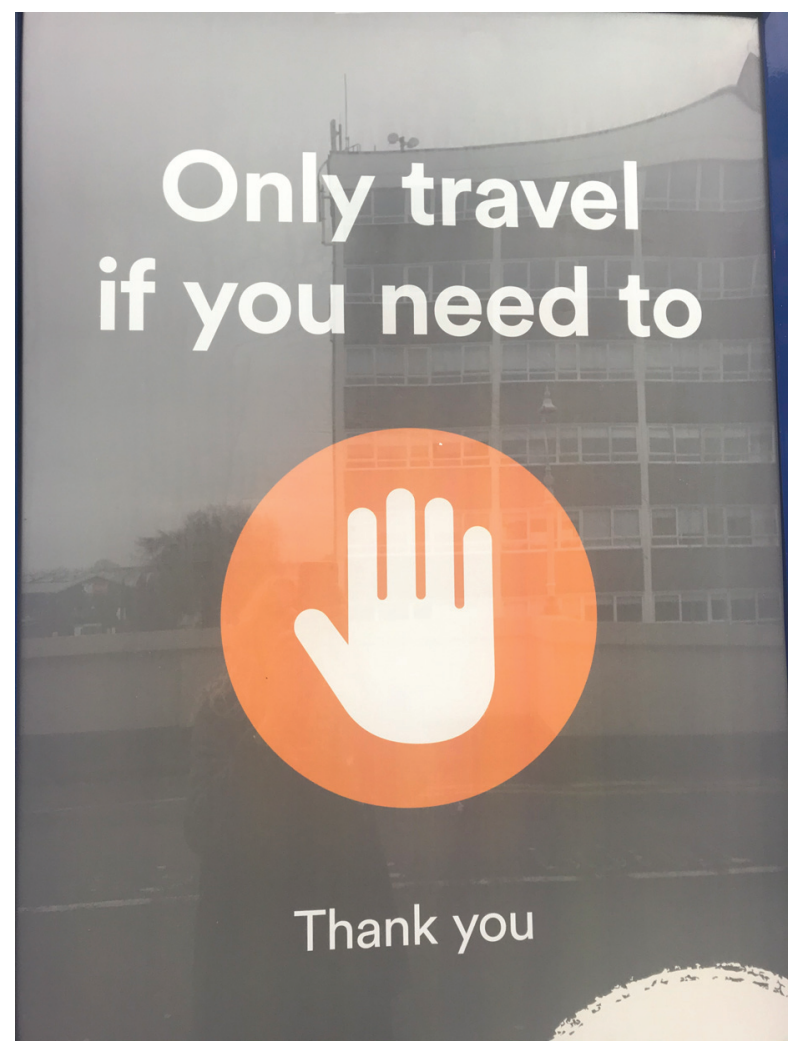

Looking towards a post-pandemic university, more ecological approaches are being explored which could help shift rational policy discourse to something more positional. Alternatives to the current model may help to restore subjectivity, agency and identity for individuals and within teaching contexts, to look beyond the cancel culture of excellence. We need to be cognisant though that a commodification of subjectivity could also take place, via widespread digitalisation (De Vos, 2020). This could reconfigure the conditions for knowledge production and alter beyond recognition what we currently believe to be human. Whether these new scientific paths lead to emancipation or alienation could therefore depend heavily on perceptions of educational purpose and on universities continuing to 'engage explicitly with values in our decisions about the direction of education' (Biesta, 2009). 
1.1 What Gets Included and What Becomes Excluded

Referring to recent decades, Biesta (2009) highlights a 'remarkable rise in interest in the measurement of education' and educational 'outcomes' to support the banner of 'raising standards' in teaching. Many competitive league tables and comparative studies have also accompanied this culture of measurement. These provide information on how national institutions and international education systems perform alongside each other. Biesta points out the irony in adopting this form of accountability that (in a McDonaldised fashion) 'is often limited to choice from a set menu and thus lacks a real democratic dimension' (Biesta, 2009). This leads into questions therefore on what exactly gets included and what else gets missed out in such a culture of measurement? When new teachers in universities undertake an academic practice certificate (such as a Postgraduate Certificate for $\mathrm{HE}$ ) they become aquainted with a wealth of educational theory that crosses disciplinary boundaries. They are required to reflexively explore their identity as a teacher, to learn how to design taught courses that may help students to learn, to undertake a research project to explore their own teaching practice and to participate in reciprocal peer review processes. A new lecturer will therefore need to make value-based judgements on methods to adopt across diverse contexts and cohorts of students. Teacher positionality is therefore complex and fluid and enmeshed in the power relations and contexts encountered (Torres, Olave \& Lee, 2019).

This pathway of teaching development as critical practice based on personal, value-based judgements seems to sit uncomfortably with any generalised notion of excellence or best practice. Yet policies adopted for measuring excellence, outcomes and employability prospects for students have pre-defined variables, categories and attributes that surveys seek to quantify. The accompanying policy discourse has emphasised rational, systematic forms of improvements as goals, which seems to irrationally exclude the diversity of critical methods and reflexivity that a new lecturer is required to assimilate during their academic practice certificate. This contradiction leads into the issue of whether we are simply adopting generic categories that appear easy to measure, or whether we are actually measuring what we really value (Biesta, 2009). Closely related to this dilemma is an emphasis on performativity that 'requires individual practitioners to organize themselves as a response to targets, indicators and evaluations'. This means that teachers must 'set aside personal beliefs and commitments and live an existence of calculation' (Ball, 2003: 215). Such a regulation of performance can leave teachers with little human agency to perform. It also produces opacity in organisations rather than transparency. As professionals compete to 'realise their potential', this can also marginalise less instrumental routes to knowledge in HE (Hayes, 2019a: 24). Biesta points 
to a further problem where performativity can build a 'culture in which means become ends in themselves so that targets and indicators of quality become mistaken for quality itself'. Furthermore, this can lead to only certain topics that seem to fit this judgement of quality being funded for research, based on 'this particular methodology in order to generate scientific knowledge' to add to the list of 'what works' (Biesta, 2009).

\subsection{Adding Items to the McPolicy Menu in Order to Measure Them}

As well as omitting important aspects of authenticity, positionality and reflexivity that new teachers engage with, there are other problematic assumptions linked to inclusivity when only some pre-selected items join the McPolicy menu to be measured. Whilst a startling number of general policy topics are now addressed in university strategy documents, these themes tend to sit apart from each other as if such matters affect students or staff, in isolation from each other. Repeated attempts to 'fix' societal issues (such as student engagement, employability, sustainability, digital capability, wellbeing, inclusivity and mental health) by educationalising these into university strategies, seems to result in documents that fail to address combinations of these themes. Students are likely to be experiencing further challenges that do not get a mention but that intersect across several of these areas, as any lecturer who is also a personal tutor will testify. As an example, a policy aiming to address discrimination may not necessarily refer to forms of algorithmic exclusion or cancel culture in the same policy that addresses digital capability. As more ecological approaches towards education to support sustainability emerge, the interdisciplinary collaborations anticipated need to be reflected in converged policies. Just as measuring excellence has focused on a menu of isolated variables to aid audit, ecological approaches towards teaching quality recognise the messy postdigital contexts that teachers now occupy and their unique, fluid, positionalities within these.

\subsection{Educational Purpose Will Differ across Contexts}

Biesta (2009) suggests though that there is a 'remarkable absence in many contemporary discussions about education of explicit attention for what is educationally desirable'. Instead the focus remains on 'educational processes and their improvement but very little about what such processes are supposed to bring about'. This may perhaps be because 'the question of educational purpose might be seen as too difficult to resolve' and also because 'ideas about the purpose(s) of education are seen as being entirely dependent upon personal - which often means: subjective - values and beliefs about which no rational discussion is possible' (Biesta, 2009). It would seem therefore that the 
more democratic discussions concerning educational purpose largely get left within the sessions on the Postgraduate Certificate for HE and may get little airing in the wider institutional context outside. Biesta suggests that HE has come to rely on 'a particular commonsense view of what education is for'. It is a view though, that 'often serves the interests of some groups (much) better than those of others' (Biesta, 2009). This view could take the form that 'what matters most is academic achievement in a small number of curricular domains, particularly language, science and mathematics', a view that is constructed mainly with a focus on the 'qualification function of education'. However, for some students, vocational skills may be more important than academic knowledge depending on 'the access such knowledge gives to particular positions in society' (Biesta, 2009). It is therefore not hard to see how social inequalities via education can become reproduced.

\subsection{The Rise of Learning and the Decline of Education}

The issue discussed in the previous chapter, where an increased emphasis on 'learning' has led to a decline in the concept of 'education' has impacted on how teachers are now positioned as 'facilitators' of learning and learners, rather than teachers of students (Biesta, 2009). Education in turn becomes a much larger container into which the provision of learning opportunities or learning experiences' has attracted an array of additional elements that now cluster under 'the student experience' which McPolicy seeks to measure in terms of 'enhancement' and 'value for money' (McRae, 2018). Teachers are then required to 'encourage, support and celebrate' fabricated concepts like 'best practice' that might be measured in terms of how much this can enhance other fabricated concepts like 'the student experience':

Encourage, support, and celebrate innovations and best practice to enhance the student experience. (Hayes, 2019a: 19)

Such statements leave out an abundance of what might have been said concerning education, which becomes recast with a sole focus 'in terms of learning and learners' (Biesta, 2009). Biesta attributes a combination of factors to this situation, including new theories of learning, process driven roles, a huge rise in informal learning throughout people's lives, the erosion of the welfare state, and the rise of neoliberal policies in which the individual is prioritised as a learner consumer. Whilst a number of these could be empowering, the accumulative effect can be to structure some 'ways of thinking, doing and reasoning to the detriment of other ways of thinking, doing and reasoning' (Biesta, 2009).

Biesta raises the issue that firstly, a learner focus is basically an individualistic concept. Thus it 'stands in stark contrast to the concept of education 
which always implies a relationship: someone educating someone else and the person educating thus having a certain sense of what the purpose of his or her activities is'. Secondly, learning is basically a process term. It denotes processes and activities but is open - if not empty - with regard to content and direction' (Biesta, 2009).

\subsection{Measuring Human Intelligence Based on Which Educational Theories and Values?}

The detachment of learning from education (and in turn from the associated relationships that education involves with people and pedagogy) and the treatment of learning as process-oriented makes learning ripe for an application of AI in this vein. Luckin (2O2O) argues that AI enables smarter ways to 'understand ourselves, the world and how we teach and learn':

For the first time we will be able to extend, develop and measure the complexity of human intelligence - an intellect that is more sophisticated than any AI. This will revolutionise the way we think about human intelligence. (Luckin, 2020)

But, 'revolutionise the way we think about human intelligence' from which point of view? There are indeed many as any trainee lecturer will attest. If there were not abundant approaches for thinking about human intelligence, then an enormous wealth of educational and interdisciplinary literature and staff development roles might as well be dispensed with. Perhaps this is a consideration. As mentioned earlier, new teachers are trained to be educators through perspectives that cross disciplinary boundaries. They are required to reflexively explore their unique identities as educators as they develop techniques and design activities for diverse contexts and cohorts of students. Students come in every variety, background, age group, culture and bring their own visions and needs. If AI is to be applied in ways that might be empowering, then it is necessary to question the route through which such systems have been developed and designed and are likely to then be deployed. It is not enough to bring in AI techniques without both interrogating the commercial background and educational theory behind them, any more than we would recruit a new teacher to take responsibility for a taught programme, without checking their qualifications, inclusive practice and experience to teach.

\subsection{A 'Track and Trace' on the Background to AI in Education}

Williamson and Eynon (2020) have examined some of the historical threads connected with AI in education as well as future directions. In an editorial to a recent special issue that they convened, they discuss a range of interests, 
ethical and social implications that can get overlooked in the 'current hyperbole' surrounding AI in education (AIEd). They include the background and links to sets of 'associated ideas about adaptive systems, pedagogic agents, personalized learning, intelligent tutors, and automated governance' (Williamson \& Eynon, 2020: 224) and suggest that rather than a linear history, a convergence is taking place of many 'genealogical threads'. These include:

1. several decades of AIEd research and development in academic centres and labs

2. the growth of the commercial education technology (edtech) industry

3. the influence of global technology corporations on education

4. the emergence of data-driven policy and governance.

Their genealogical analysis approach therefore 'tracks and traces', so to speak, 'how contemporary practices and institutions emerged out of specific struggles, conflicts, alliances, and exercises of power'. This includes contingent processes, disciplinary conflicts and encounters, funding schemes, 'methodological advances and sectoral encounters between academic research and commercial imperatives' (Williamson \& Eynon, 2020: 224). Tracing such links, as well as the effects of Covid-19 in accelerating these interests, is a reminder of the powerful dialectics between universities and the flow of commercial edtech interests and alliances connected through the virtual airing cupboard. If these dominant and controlling trajectories are not highlighted, then a digitalisation of human intelligence can happen very quickly, without much examination of the blueprints that lie behind it.

\subsection{McAI Values Support Efficiency, Calculability, Predictability and Control in Education}

In Ritzer's McDonaldisation thesis (2018) the key techniques of rationalisation described are: efficiency, calculability, predictability and control.

These dimensions are supported across many contemporary institutions through the ability to train computers to perform tasks without human intervention. This detachment from people has proved to be rather useful during the pandemic with renewed interest in deploying robots to undertake basic cleaning and administrative tasks and reduce risk of person to person contact with the virus, along with the incessant need for sanitiser (Figure 40). Given that 'McDonaldisation is a force for increasing global homogeneity' (Ritzer \& Dean, 2019: 188) though, it is worth bearing in mind the fifth dimension of McDonaldisation: irrationality of rationality. In universities, when does increased homogenisation (evidenced for example through emphasis on 'best practice' and 'the student experience') move the rationality behind AIEd concerning predictability, as just one example, into a problematic irrationality? 


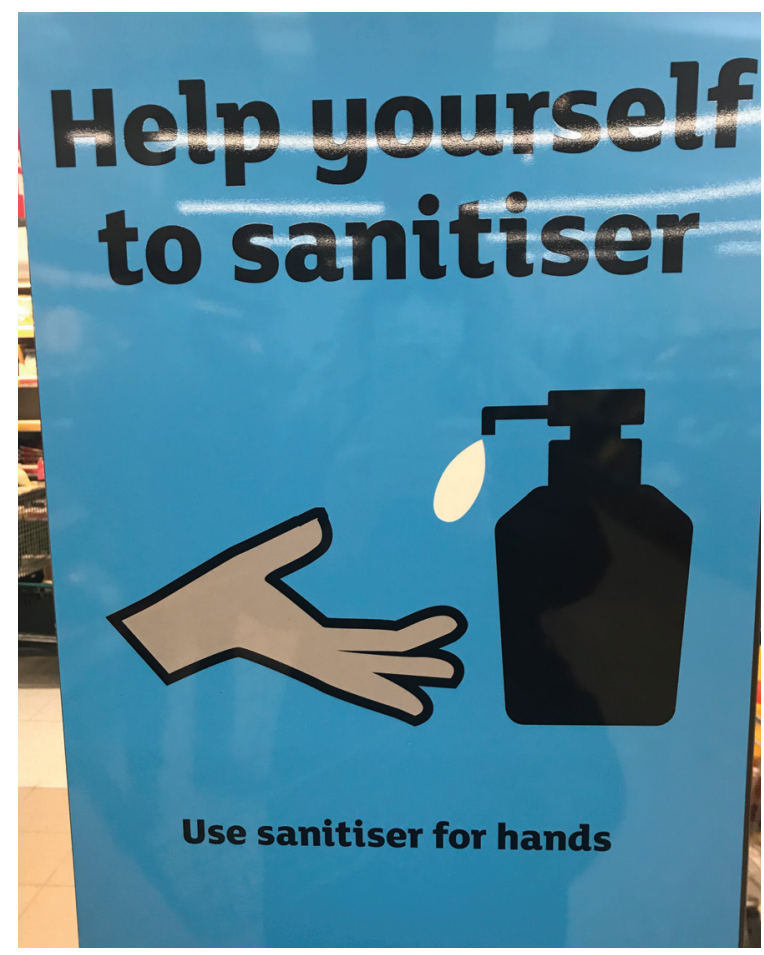

FIGURE 40

A sign reminding people to use sanitiser

Perotta and Selwyn (2020) have examined scholarly work carried out by data scientists around the use of 'deep learning' to predict aspects of educational performance. They take into account a wealth of theory from Science and Technology Studies (sTs) and report issues with 'units of analysis: flawed data, partially incomprehensible computational methods, narrow forms of educational knowledge baked into the online environments, and a reductionist discourse of data science with evident economic ramifications' (Perrotta \& Selwyn, 2020: 251). They argue that, particularly when framed ethnographically, doubt is cast on AI as an objective scientific endeavour. Given the converged routes that AI has developed along, where emphasis has been placed on 'epistemic expertise in the learning sciences and educational data science that is related to, but not reducible to, commercial and economic interests' (Williamson \& Eynon, 2020: 226) there are a particular set of values travelling comfortably and silently with AI into universities, and into the lives of teachers and students.

This has far reaching implications in a discussion of postdigital positionality where emphasis is placed on empowerment through deeply individual educational encounters. These cross multiple intersections that relate to the positionality of each individual teacher, which is complex and fluid, enmeshed in power relations and contextually bound (Torres, Olave \& Lee, 2019). Instead 
'AI techniques of 'automated knowledge discovery' such as pattern recognition and correlational analysis are based on a mechanical, inductivist epistemology that assumes all patterns are interpretable in the same standardized ways across all cultures and contexts' (Williamson \& Eynon, 2020: 226).

\subsection{Automating Empowerment or Inequality}

Standardised interpretation across cultures and contexts bypasses a wealth of interdisciplinary knowledge. This includes educational techniques with disadvantaged individuals and groups across global and local contexts. For example, a raft of work by universities on education for sustainable development seems to be treated as something of a trajectory that does not feed back into core institutional education policy. In our research on Learning through the Crisis for the DFID EdTech Hub (Traxler, Smith, Scott \& Hayes, 2020) our Delphi technique revealed repeated agreement from experts in development education and policy from across the globe that 'context is king. The Covid-19 pandemic has provided many insights to local and global contexts of disadvantage where the challenges facing teachers and students are not so different, but what is being learned reflects the positionality of those involved (Jandric \& Hayes, 2020a, 2020b). Others emphasise a deeply relational nature of teaching and learning, where no 'complex problems can be effectively solved by one autonomous component' (Czerniewicz et al., 2020). There are therefore many potential learning practices, processes and theories within our so-called knowledge economy that fail to connect and inform our approaches towards inequalities. There are powerful postdigital dialogues though at our fingertips, but these need to also cross disciplines, sectors and locations to inform new personal and plural understandings.

This is a perspective that is also echoed through the intersectional HCI studies discussed in Chapter 2. It is important to learn how AI has been applied in a wider community context to inform how it might empower rather than exacerbate inequalities. In Virginia Eubanks' (2018) Automating inequality: how high-tech tools profile, police, and punish the poor, locational studies and observations provide rich insights into the flaws of algorithmic predictions. These are flaws though, that intersect with societal arrangements regarding gender, class and race, policies for welfare reform and digital deprivation. Eubanks refers to these constitutive elements creating a 'digital poorhouse' of the twenty-first century, but the effects are rapid and at a larger scale. There are much greater complexities than in the case of the physical poorhouses that existed in previous centuries, yet many struggles involve the same racial and class-based fights for social justice. 
These observations make it necessary to reintroduce the very broad nature of education, from the most basic concerns about child or adult literacy right through to the most advanced scientific and philosophical reasoning and research. From literacy in language, digital skills, data, or all of these and other literacies, may now require a new hybrid concept to refer to where these integrate. The connections for example, with how 'citizen literacy' (Casey, 2020) might develop at the intersections where biology, technology, economy and politics meet are not separate from university recruitment, participation and retention or from equality, diversity and inclusion agendas. At the same time as discussing the very latest biodigital advances, there are questions to consider relating as to how literacy is now enacted by citizens. Universities now need to address these complexities in a more organic approach towards policy, if they hope to widen participation. They need to engage with deeply interconnected questions if institutions hope to broaden opportunities for diverse learners. Such concerns cannot be separated from new techniques that fall under 'precision education' (Williamson, 2019), where interdisciplinary educational science is focused on 'the quantification of students' affects, bodies and brains'. Wealthy investors and philanthropic donors are involved alongside commercial entities, university researchers and scientists:

Set in the context of intensive scientific advances in the biological sciences, including psychophysiology and biometrics, neuroscience and genomics, precision education raises fresh questions about the intersections of biology with society, politics and governance. (Williamson, 2019)

Education has always needed a spread of provision and techniques to reach society's most disadvantaged. It is currently hard to visualise whether all citizens can, will or even should be, absorbed into such advances (Peters, Jandrić \& Hayes, 2021c). In Brain Culture: Shaping Policy through Neuroscience, Jessica Pykett (2015) argues:

Learning can never be understood simply as a brain process. Rather, there are high political stakes in neuroscientific explanations of the learning process in terms of delimiting learning norms and dealing with learning differences in real places. Education is more than the aggregate sum of people learning. The shaping of conduct, behaviour and educational outcomes is a social and cultural endeavour essential to the governing of citizens in specific contexts. The brain of the learning person is not just an algorithm to be optimised. 
Therefore, a focus on 'learners' alone cuts off the flow of contextual knowledge that teachers and students from all manner of locations bring to this debate. Projects like Republic of Learning (Garnett, 2019) encourage self-determined places of learning. A strong emphasis is on positionality means that individuals represent their learning however they wish. This is different though to a trend towards 'personalised learning' that only sounds empowering in its application of AI to connect with the individual positionality of students. This is critiqued for encouraging rational, simplistic views of 'learner-centred' education (Knox, Wang \& Gallagher, 2019) and individualistic discourse that overemphasises market-inspired logics and the interests of technology companies through metrics, automation and the pervasive collection of data (Perrotta \& Selwyn, 202O). In contesting these issues, there is also the need to put forward alternative, more empowering discourses for AIEd:

In this sense, AI in education needs to be talked about more often in controversial and circumspect terms, rather than accepted as a computational fait accompli. (Perrotta \& Selwyn, 2020: 267)

It is therefore necessary to continue a debate about teaching with technology that has been ongoing and reshaping for decades concerning the 'technological means-end model' (Hlynka \& Belland, 1991: v) that McPolicy endorses, and what alternatives might now be open to us.

\section{Finding New, Personal and Plural Starting Points from Which to Teach}

The starting point that McPolicy has bestowed on each of us thus needs to be re-evaluated. This is because it is 'a politically imposed discourse, which is to say that it constitutes the hegemonic discourse of western nation states' (Olssen \& Peters, 2005: 314) thus diverting us from other potentially richer dialogues emerging from different nations and in a postdigital context. In seeking to measure excellence and improve outcomes in $\mathrm{HE}$, a set of rational starting points have been introduced. These share similarities with dimensions of McDonaldisation, where humans have been 'valued' in a particular (rather functional, but also increasingly disposable) manner as observed in the running of fast food outlets (Ritzer, 1993). They have also been positioned in a particularly disempowering manner, in relation to the emphasis on technology for enhancing learning in McPolicy that omits human labour and values (Hayes, 2019a). 
Penny Welch (2020) argues that:

The subordination of human values to market values within the higher education system today detracts enormously from its success in extending opportunities to students, providing jobs for staff and contributing to local economies. Any claims made for excellence are hollow when the achievements of institutions come at the expense of the wellbeing of students and staff. Academic analysis, collective campaigns and individual actions that promote human values have never been more necessary.

Taking a pause to consider how we might voice alternative, exciting and empowering perspectives that are drawn from different, more personal and plural starting points, is the essence of what this book is about.

\subsection{Postdigital Perspectives on the McPolicy of Measuring Excellence}

In a recent special issue in Postdigital Science and Education journal a range of different views are taken to critique the 'measuring of excellence' in HE, taking a postdigital perspective (Hayes, 2020).

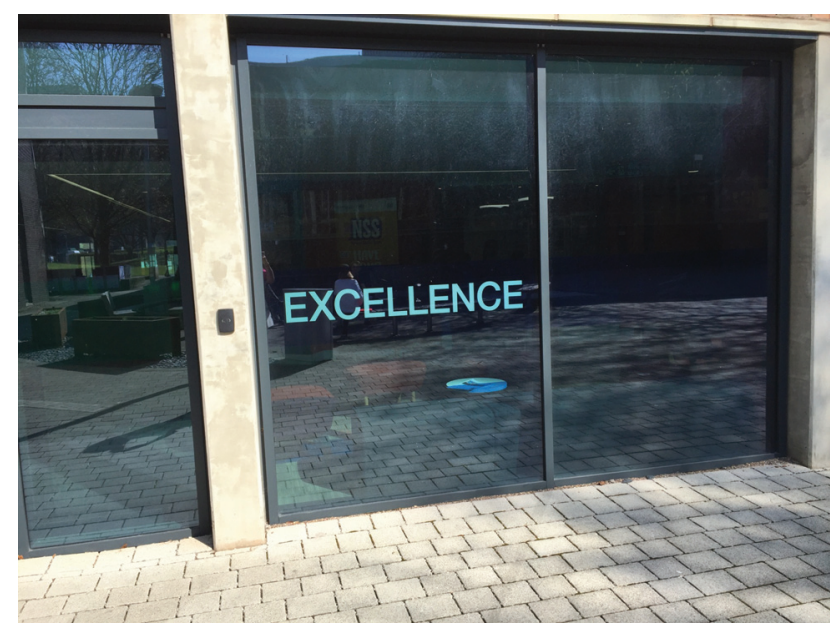

FIGURE 41 University iconography where a window is inscribed with the word 'EXCELLENCE'

The measuring of excellence has become a familiar but disputed notion in universities, despite the etching of such words into windows (Figure 41).

Dennis Hayes argues that unquestioning compliance with this concept ignores a responsibility that academics have 'to refuse to be told what to think', as such, we each have a duty towards academic freedom that overrides any 'rationality of governance' (Hayes, D., 2019). Over decades of measuring efficiency via an 'audit culture' (Shore \& Wright, 1999) this has emphasised certain 
teaching outcomes at the expense of others. Teaching staff have been required to acquire higher levels of recognition for their 'excellence' by mapping themselves to national frameworks of recognition. However, research undertaken by Warnes (2020) found that there was little impact on teaching quality itself from the award of higher fellowships. Instead recipients did not change practice, perceiving that they were 'already excellent', their managers showed little interest and their students were mainly unaware of their receipt of excellent teaching awards (Warnes, 2020). As well as the problems of measuring teaching excellence, applying measurement to research has brought one 'particular concept of research excellence into being' (Jandrić, 2020) at the expense of others. As a result, universities have tended to segregate their policies related to innovative digital and scientific research from their policies aimed at inclusive practices in teaching. Not only are important dialectical relationships between the practices of research and teaching at risk in this rational approach, irrationalities are surfacing in this separation across policy too.

As Covid-19 has illuminated human dependencies on digital platforms for teaching and research it has also revealed the problems of trying to control diversity and inclusion within the boundaries of a university that no longer exists. Universities have been forming public/private partnerships across recent decades that have taken advantage of the 'pervasive and ubiquitous connectivity and mobility' afforded by the virtual airing cupboard. This has, at the same time, been 'profoundly transforming the production, ownership, distribution and nature of learning and knowing and problematising the role and status of universities and lecturers' (Traxler, 2020). There are new data flows between the digital infrastructure of universities and the commercial platforms and companies they have built alliances with. Extracted data is used for aggregation, analysis, and monetisation (Komljenovic, 2018, 2020). Therefore, universities are no longer environments set apart from the outside world selecting who or what they will or will not engage with. The focus has shifted towards the importance now of 'the inclusion of the higher education system into the world outside' (Traxler, 2020). Traxler discusses factors that are 'threatening to overturn a world of steady change and stable argument' (Traxler, 2020) that our HE policies have for so long been based on. As such, 'our capacity to understand, let alone measure, these and their relationship to equity and education will be poorly understood for years to come' (Traxler, 2020).

\subsection{Regional Positionalities and Place-Based Debate}

Whilst universities are often discussed as an HE sector, this can detract from the considerable diversity that exists between institutions, their activities, priorities, focus and surroundings. These institutional positionalities are important 
to remember in a context where homogeneity can silence regional voices and diverse contributions to this debate. As such:

territorially agnostic discourse about universities, downplays institutional history and purpose, risks concealing innovative practices, and fails to tackle entrenched inequalities. (Hayes, Jopling, Hayes, D, Westwood, Tuckett \& Barnett, 2020)

In raising this challenge, there is a value and role for live, place-based debate in HE institutions to highlight distributional inequities concerning funding, raise local voices from the community and connect these with national policy. Even though such debate has had to take place virtually during the Covid-19 pandemic, such events provide opportunities to voice 'the essential part that regional universities play in connecting global technological and biological change, with local social projects, citizens and industry' (Hayes et al., 2020). They open space too, for recognition through postdigital perspectives that Covid-19 does not sit apart from other political economic challenges for teachers, students, researchers and policy makers in HE and beyond. Whilst HE policies may address many topics separately in live debate they are discussed simultaneously. These take on a more organic and transparent nature during live debate, raising the regional academic voices that are all too often silenced by the data-driven measures of excellence that currently dominate policy.

\subsection{A More Ecological Model}

The measurement of excellence model of the university will always encounter issues where activities (such as valuable live debate) are not easily quantified. The emphasis placed on evaluating simplistic notions of processes and isolated variables simply leaves universities constrained in their operations, and also vulnerable. Barnett (2017) argues that in universities we are currently failing to see the ecological nature of our activities, that the ecological university is upon us, ahead of us, and here even now:

But we do not see it, being blind to its presence. Its manifestations are unrecognised, so blinkered are we by the dominant ideologies of our age, in much of what matters in higher education is that which generates income and secures markets, positioning in world rankings and student satisfaction. (Barnett, 2017)

Barnett proceeds to point out that 'ecology' hints at the character of the situation and an interconnectedness, where the university is 'increasingly 
interconnected with so many facets of the world, human and non-human'. He argues that the university is neither in crisis nor in ruins but it is instead 'falling woefully short of its responsibilities and its possibilities in the world' (Barnett, 2017). There is a longer history to such calls for ecological approaches in academia, including the 'three spheres of ecology' (environmental, social and mental) discussed by Guattari (2000) and prior to that the 'ecology of mind' proposed by Gregory Bateson (Bateson, 1972, Stratford, 2015).

In The Eco-university in the Green Age, Michael Peters (2016) traces a 'conceptual ancestry' for the term 'eco' pointing to its root in both ecology and economics (Peters, 2016: 6o). He describes the eco in ecology in terms of its 'relationship of living organisms to their environment' and the eco in economics as the management or stewardship of this. There are relations across these ideas that deeply connect with how the contemporary university might shift in focus. Our currently largely managerial focus is on the eco in economy, where our political economy of neoliberalism, processes of McDonaldisation and discourse of McPolicy dictate the path of education. If a more balanced approach where the environment, place and context surrounding each of us (in terms of positionality) becomes a reality, then there is a possibility for radically altering the discourse. Peters argues that the debate on whether the household, estate or environment around us is a discipline or a branch of knowledge has a long history but by the end of the eighteenth century what we refer to as 'political economy had severed its ancient links' (Peters, 2016: 62). Peters describes a 'conceptual and epistemological tug-of-war' between 'science on one side, with a mainstream, "no-limits-to-growth" economics of development' or modernisation and 'a Romanticist anti-modernism' which 'by contrast, attempts to hold onto organicist metaphors, resists the instrumental rationality that characterises the perceived positivism of the sciences, and courts "deep ecology" principles, "local knowledge" and the naturalism of other cultures' (Peters, 2016: 66).

\subsection{Changing Curriculum and Policy to Reflect a Sustainable Global Digital University Ecosystem}

So here we have it, in terms of a much longer background to the 'measuring' that we seem to have become obsessed with right now in universities and the marginalisation of context and positionality. There is, as Peters puts it, a longstanding opposition:

the whole intersecting matrix of grand narratives of modernism and its oppositional anti-modernist counter-narratives - which, incidentally is still very much part of the on-going "culture wars" of the early twenty-first 
century, is fundamental to understanding how we might break free of this controlling dualism, and thus move beyond modernity. (Peters, 2016:67)

It is necessary to understand a new interdisciplinary and integrative science in order to address sustainability. This new integration requires changes to the curriculum, to education of students and new postdigital ecopedagogies that help us navigate 'genealogies, contradictions and possible futures' (Jandrić \& Ford, 2020). It brings new points to consider in the design of postdigital learning and teaching (Matthews, 2019) and in the evaluation of teaching quality in more ecological and less rational, datafied ways (Fawns, Aitken \& Jones, 2020). Peters argues that a fundamental starting point:

is signified in the "eco" root meaning shared by ecology and economy. It provides the basis for various conceptions of the university and higher education in general in its contribution to knowledge economies and ecologies within the concept of the emerging global digital university ecosystem. It includes not only the advent of social media, knowledge sharing and collaboration, but also the development of "big" publishing systems, the emergence of "big data", open access and other innovations in the field of academic publishing. The dual cross-over purpose is the question of a going beyond a productionist metaphysics that dominates the industrial age, to a new ethos and new possibilities for exploring the post-industrial green or sustainable economy. (Peters, 2012)

These are questions that we have turned to in a collection of articles (Peters, Jandrić \& Hayes, 2021a, 2021b, 2021c) that also inform a larger forthcoming project in the edited book: Bioinformational Philosophy and Postdigital Knowledge Ecologies. Singapore: Springer. This compilation will explore how the new ecological possibilities of the bioeconomy offer alternative postdigital knowledge ecologies to the rational means-end, consumer dominated capitalism that has underpinned education for too long. There is now an urgency for the university to respond and to take up a key role in advancing understanding on these matters in the public realm. If $\mathrm{HE}$ fails to do this it will otherwise remain negatively positioned (Barnett, 2017). Reflecting on the arguments put forward by Delanty (2001: 158) earlier in this book, the university has a societal responsibility for connecting technology to citizenship, 'the solution resides in linking the challenge of technology with cultural discourses'. If the positionality of the university shifts in this way, then the McPolicy discourse may become less of a focus than these key intersubjective exchanges concerning the widespread digitalisation of humanity. 


\subsection{Developing an Inclusive, Shared Language about Education, Teachers and Students}

In their model to support a sustainable, bio-based economy (and its different focus to a KBE), Saachi, Lotti and Branduardi (2O2O) refer to 'education', not 'learning'. It is education that will help to facilitate important interdisciplinary combinations, to cross boundaries and integrate tools, language and knowledge from many different disciplines and sub-disciplines (Saachi, Lotti \& Branduardi, 2020). In their vision, innovation requires a move beyond single sector competences, where a novel and flexible educational framework can help create a shared language. They recognise that to transition to a bio-based economy entails the support of the social sciences and also a personal consciousness that can guide desirable technological transitions (Saachi, Lotti \& Branduardi, 2020). There appears to be a much stronger focus on teachers in this educational approach, but with space for broad and inclusive collaboration across teachers, other teachers and students. Given the emphasis on developing a shared language, it is hard to imagine the McPolicy rhetoric in use here. McPolicy is based on a flawed model that cannot support the above sustainable, ecological model now required. 